\title{
Blue intensity parameters derived from Ponderosa pine tree rings characterize intra-annual density fluctuations and reveal seasonally divergent water limitations
}

\author{
Flurin Babst ${ }^{1,2,3} \cdot$ William E. Wright $^{1} \cdot$ Paul Szejner $^{1} \cdot$ Leon Wells $^{1}$ • \\ Soumaya Belmecheri ${ }^{1} \cdot$ Russell K. Monson ${ }^{1,4}$
}

Received: 30 October 2015/Accepted: 29 February 2016/Published online: 18 March 2016

(c) Springer-Verlag Berlin Heidelberg 2016

\begin{abstract}
Key message A set of novel parameters extracted from fine-spatial resolution blue intensity profiles characterizes intra-annual density fluctuations in Ponderosa pine and complements information on climate sensitivity obtained from radial growth.

Abstract Rapidly rising evaporative demand threatens forests in semi-arid areas around the world, but the timing of stem growth response to drought is often coarsely known. This is partly due to a shortage of sub-annual growth records, particularly outside the Mediterranean region where most intra-annual density fluctuation (IADF) chronologies are based. We anticipate that an automated, cost-effective, and easily implementable method to characterize IADFs could foster more widespread development of sub-annual chronologies. We applied a peak detection algorithm to fine-spatial resolution blue intensity (BI) profiles of Ponderosa pine tree rings from two sites in
\end{abstract}

Communicated by E. Liang.

Electronic supplementary material The online version of this article (doi:10.1007/s00468-016-1377-6) contains supplementary material, which is available to authorized users.

Flurin Babst

flurinbabst@gmail.com

1 Laboratory of Tree-Ring Research, University of Arizona, Tucson, AZ 85721, USA

2 Dendroclimatology group, Swiss Federal Research Institute WSL, 8903 Birmensdorf, Switzerland

3 W. Szafer Institute of Botany, Polish Academy of Sciences, 31-512 Krakow, Poland

4 Department of Ecology and Evolutionary Biology, University of Arizona, Tucson 85721, USA southern Arizona ( $\sim 300 \mathrm{~m}$ elevation difference). Out of seven BI parameters that characterize IADFs, peak height, width, and area showed satisfactory chronology statistics. We assessed the response of these BI and radial growth parameters to six monthly resolved climate variables and to the onset date of the North American summer monsoon. Radial growth at the lower-elevation site depended mainly on winter precipitation, whereas the higher site relied on spring and monsoon precipitation. A regular May-June drought period promoted IADFs in early ring portions at both sites. Yet, IADFs at the higher site were only formed, if spring was sufficiently humid to assume enough radial growth. Late-position IADFs were caused by a weak monsoon and additionally promoted by favorable conditions towards the end of the growing season. The contrast between sites is likely attributable to a three-week difference in the growing season onset, emphasizing the importance of growth phenology for drought impacts on forests in the US Southwest.

Keywords Intra-annual density fluctuation - Wood density $\cdot$ Tree ring $\cdot$ Monsoon $\cdot$ Climate $\cdot$ Drought

\section{Introduction}

Water limitation driven by decreasing precipitation and/or increased atmospheric evaporative demand has been identified as a major threat for the vigor and even survival of trees in arid environments (McDowell et al. 2011; Choat et al. 2012; Williams et al. 2013; McDowell and Allen 2015). Understanding the responses of trees to water deficits is thus a prerequisite to anticipate future forest growth changes, especially at longer time scales. A primary physiological response to drought is the closure of stomata 
to reduce transpiration. Stomatal conductance is being intensely studied around the globe because it not only acts as a primary driver of the terrestrial water cycle, but it also influences the potential for forest carbon uptake (Franks et al. 2013; Frank et al. 2015; Lin et al. 2015). The ecophysiological effects of drought are an active research field (Sevanto and Dickman 2015) and recent studies have indicated that the lower turgor associated with stomatal closure reduces the transport and allocation of photoassimilates from the leaves to sink tissues, such as stem and roots (Woodruff and Meinzer 2011; Sevanto et al. 2014). Whether the carbohydrates that remain in the leaves can be allocated after the drought terminates or not may depend on its severity (Sala et al. 2010; Blessing et al. 2015), but many studies have shown that cambial activity slows down or even temporarily ceases under intense drought (e.g. De Luis et al. 2011; Vieira et al. 2015). Besides negative effects on cell division rates (Ren et al. 2015), this leads to wood anatomical changes in conifers, specifically to smaller cell lumen that are less prone to cavitation (De Soto et al. 2011). The cell wall thickness on the other hand appears to be less affected by drought conditions (Carvalho et al. 2015), potentially due to the temporal decoupling between cell differentiation and secondary wall thickening (Cuny et al. 2015). As a result, areas with increased wood density occur within annual growth rings (i.e. a higher cell wall to cell lumen diameter ratio). These areas are commonly known as intra-annual density fluctuations (IADFs; also called "false latewood bands" or "false rings").

While recent studies have identified the mechanisms of drought-induced reductions in radial stem growth, the phenology of xylogenesis in response to seasonal water limitation is less well understood (Wilkinson et al. 2015). This is in part due to a shortage of sub-annual stem growth measurements for many species in arid regions that would allow linking xylogenesis with seasonal water dynamics over long time scales. The analysis of IADFs is promising in this context because-in contrast to standard dendrochronological measurements such as total annual ring width-IADFs provide some evidence of seasonal growth dynamics. IADFs have been found in many Mediterranean conifer (e.g. Pinus pinaster, P. pinea, P. halepensis) and broadleaf species (e.g. Arbutus unedo, Erica arborea), and also in tropical hardwood species (Tectona grandis; Die et al. 2012; Venegas-Gonzalez et al. 2015). Based on measurements of stable carbon and oxygen isotope ratios of wood cellulose from the IADF area, recent studies have shown that IADF formation reflects prevailing patterns of stomatal conductance and photosynthetic water-use efficiency (Battipaglia et al. 2010, 2013).

Different types of IADFs have been identified in conifers, including latewood-like cells in the earlywood and earlywood-like cells in the latewood portion of the tree ring, which retain different seasonal climatic signals (Campelo et al. 2007; De Luis et al. 2011; Szejner 2011). Existing chronologies are based on visual assessment (e.g. Novak et al. 2013), cell characteristics extracted from microphotographs (De Micco et al. 2013) or thin sections (De Micco et al. 2012), X-ray densitometry (GonzalezBenecke et al. 2015), or sub-annual carbon and oxygen isotope ratios in the wood (Battipaglia et al. 2010, 2013). Some species appear to be more plastic in their xylogenesis than others (Camarero et al. 2010), but the existing literature has drawn a clear picture of IADF formation in the earlywood portion of the tree ring being driven by seasonal water shortage (e.g. Vieira et al. 2010; Olivar et al. 2012; Nabais et al. 2014). In addition, there is consensus that IADFs are more abundant in larger rings (i.e. in dominant or young trees; Copenheaver et al. 2006; Vieira et al. 2009; Bogino and Bravo 2009; Campelo et al. 2015).

While the existing literature has demonstrated both the use and potential of IADFs to provide information on seasonal stem growth dynamics, their application is still not abundant enough to enable a synthesis for trees from a range of different forest biomes. For instance, the vast majority of IADF chronologies have been developed in Mediterranean environments that experience a climate regime with a rather unimodal precipitation distribution (i.e. wet winter and dry summer; although isolated precipitation events during the summer months are possible). These data have yielded valuable information on the influence of summer drought on tree growth, but often the timing of IADF formation could only be coarsely attributed to a season. This is due to the lack of a reliable time marker for the end of the drought period that could be associated with the termination of the IADF. Such a time marker exists, however, in arid areas with bimodal precipitation distribution (i.e. wet winter, dry spring, wet summer, dry autumn) such as occurs in the US Southwest. In southern Arizona and New Mexico, the onset of the North American Monsoon (NAM) terminates a pre-summer drought period that regularly causes IADFs in trees growing near the dry margin of their distribution range (e.g. Leavitt et al. 2002). Hence, the section of the tree ring after the IADF is considered to be influenced by precipitation from the NAM, whereas the earlier part is influenced by winter precipitation (Griffin et al. 2011). This separation has been used for palaeoclimatological purposes, specifically for the development of long early- and latewood width chronologies used in biannual precipitation reconstructions (Griffin et al. 2013). However, more efforts are needed to extract information on environmental dynamics contained in the size and intensity of the IADFs themselves.

We anticipate that an efficient and cost-effective methodology to measure IADF parameters could foster more widespread development of sub-annual chronologies. 
Here, we propose a novel approach to quantify the size, strength, and position of IADFs based on blue-light intensity measurements (BI; McCarroll et al. 2002; Campbell et al. 2007, 2011). These measurements yield a fine-spatial resolution pseudo-density profile of each tree ring that we assessed to isolate and characterize IADFs. We tested our approach in mature Ponderosa pine (Pinus ponderosa) trees from two neighboring mountain ranges in southern Arizona to answer the following questions: (1) are BI measurements suitable to characterize IADFs in conifers? (2) Is there common variability among the studied trees in terms of IADF position, size, and intensity? (3) Does cambial age affect IADF formation in Ponderosa pine? (4) What are the climatic drivers of IADF formation in the NAM domain?

\section{Materials and methods}

\section{Study area}

The study sites are located in two neighboring mountain ranges in southern Arizona that belong to the Sky Islands (Table 1). These forested "island" mountains emerge from arid landscapes in southern portions of the US Southwest and are characterized by distinct altitudinal vegetation zones, ranging from lowland desert vegetation, over Pinon pine-Juniper shrubland, to coniferous forests at high elevation. The vegetation in this region is strongly limited by moisture availability, which increases with elevation (0.4-3.8 $\mathrm{mm}$ per $100 \mathrm{~m}$, depending on the season) and shows a bimodal intra-annual distribution (Fig. 1). Precipitation falls during the cold season (November-March) in the form of westerly frontal systems that originate from the Pacific Ocean. A second rainy season starts with the onset of the NAM in late June or early July that is induced by a thermal low over northwestern Mexico and transports moisture from the Gulf of California northward along the Sierra Madre mountain range (Higgins and Shi 2001). The resulting convective thunderstorms terminate an intense pre-summer drought period that triggers IADF formation in many coniferous species (Griffin et al. 2011). The core NAM season ends in mid September.

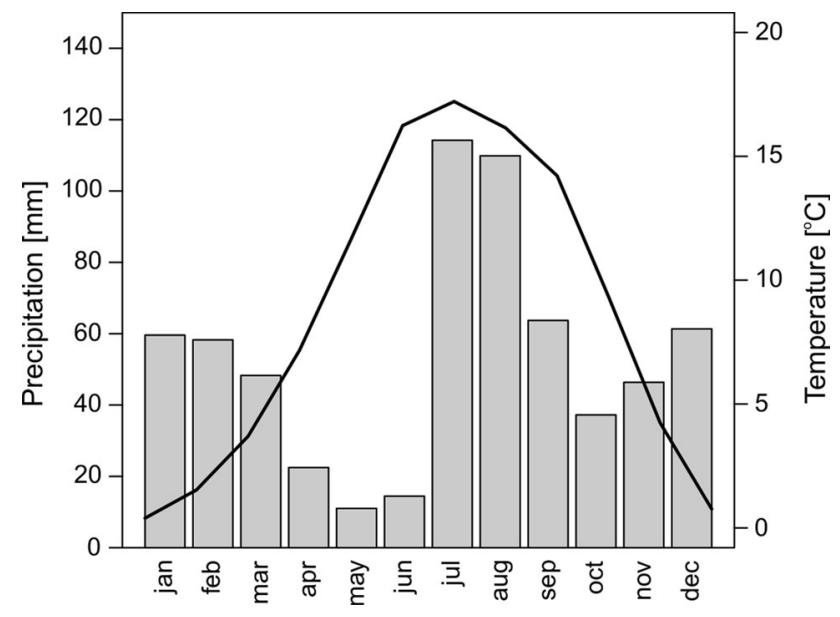

Fig. 1 Mean monthly air temperature and precipitation sum at the Palisade Ranger Station (Arizona, USA) over the 1932-1995 period. The long-term meteorological station is located at $2430 \mathrm{~m}$ a.s.l. in the vicinity of the Santa Catalina site

\section{Sample collection and ring-width measurements}

Our sampling focused on the lower elevation, dry montane forests in the Santa Catalina and Pinaleño Mountains, where Ponderosa pine is the dominant species. Site selection was facilitated by earlier work (e.g. Leavitt et al. 2002) and we chose moderately drought stressed trees with regard to micro-topography to ensure regular IADF formation. We collected two to three increment cores to the pith of mature and healthy trees in Fall 2014. These samples were prepared according to standard dendrochronological procedures (Schweingruber 1983), including drying and sanding of a horizontal surface perpendicular to the fiber direction. In preparation of the BI measurements, the resin was extracted from all samples for $20 \mathrm{~h}$ in a Soxhlet apparatus containing $99 \%$ ethanol (Campbell et al. 2011). Subsequently, the wood surface was polished with sanding paper down to $15 \mu \mathrm{m}$ grate. From all samples, we measured earlywood width (EWW), latewood width (LWW), and total ring width (TRW) using the WinDendro software (Regents Instruments Inc.). These measurements were visually and statistically crossdated using the program COFECHA (Holmes 1983) to ensure correct dating. Missing rings occurred almost exclusively in the years

Table 1 Site characteristics

\begin{tabular}{lll}
\hline & Santa Catalina Mountains & Pinaleño Mountains \\
\hline Latitude $\left(^{\circ}\right)$ & $32.407057 \mathrm{~N}$ & $32.647905 \mathrm{~N}$ \\
Longitude $\left(^{\circ}\right)$ & $110.705026 \mathrm{~W}$ & $109.816954 \mathrm{~W}$ \\
Elevation (m a.s.1.) & 2330 & 2050 \\
Species (trees) & Pinus ponderosa (8) & Pinus ponderosa (6) \\
Chronology ( $>$ 5 trees) & $1932-2014$ & $1921-2014$ \\
Closest Meteorological Station & Palisade Ranger Station (2430 m a.s.1.) & Safford (900 m a.s.l) \\
\hline
\end{tabular}


2002 and 2003 and were identified in $50 \%$ of the Santa Catalina and $15 \%$ of the Pinaleño samples. All chronologies were truncated in the year 1932 when both sites reach a sample replication greater than five trees.

\section{Assessment of intra-annual density fluctuations}

We used the blue-light intensity method to characterize IADFs in annual growth rings. This method was introduced by McCarroll et al. (2002) as a surrogate for the labor- and cost-intensive X-ray densitometry (Eschbach et al. 1995) and yields a pseudo-density profile of the measured wood sample. The BI measurements are based on red-green-blue light scans of the wood surface that can be achieved with a standard flatbed scanner (here Epson Expression 10000 XL with scanning resolution set to $2400 \mathrm{dpi}$ ). The blue channel of the digital image is extracted, as it is most sensitive to the lignin content - and thus density — of the wood. The resulting BI values are inverted compared to the actual wood density (i.e. minimum intensity $=$ maximum density and vice versa). Following the methodology described in Campbell et al. (2011), we used the WinDendro software that allows for simultaneous measurements of BI and ringwidth parameters. The standard settings of this program will output only the minimum and maximum BI that are relevant for dendroclimatological applications (Campbell et al. 2007). Here, we chose a pixel-based output to obtain the full BI profile of each tree ring. These profiles were smoothed with a flexible cubic smoothing spline (R stats package; degrees of freedom $=0.5$ times the number of pixels) to remove minor noise introduced by some features of the sample surface (Fig. 2, top panel).

We recorded the minimum and maximum BI of each annual growth ring, plus seven parameters that characterize the IADFs. These include the widely applied presence/ absence assessment (here the percentage of increment cores that showed an IADF in a given year), the IADF position and width (absolute and $\%$ of ring width), as well as the peak height and area. We applied an automatic peak detection to isolate IADFs from the BI profiles using the pracma package in $\mathrm{R}$. This procedure identified the position of the peaks and their prior and posterior inflection points (Fig. 2, bottom panel). As multiple IADFs within one growth ring were very rare, the IADF peak was defined as the highest peak that reached at least $15 \%$ of the terminal latewood peak. This threshold emerged as a trade-off between the sensitivity of the method toward low-intensity IADFs and erroneous detection of slight density fluctuations in the earlywood that were unrelated to IADFs. As a baseline for the peak height and area calculations, we approximated the "normal" BI curve (i.e. when no IADF is formed) with a tangent from the posterior inflection point

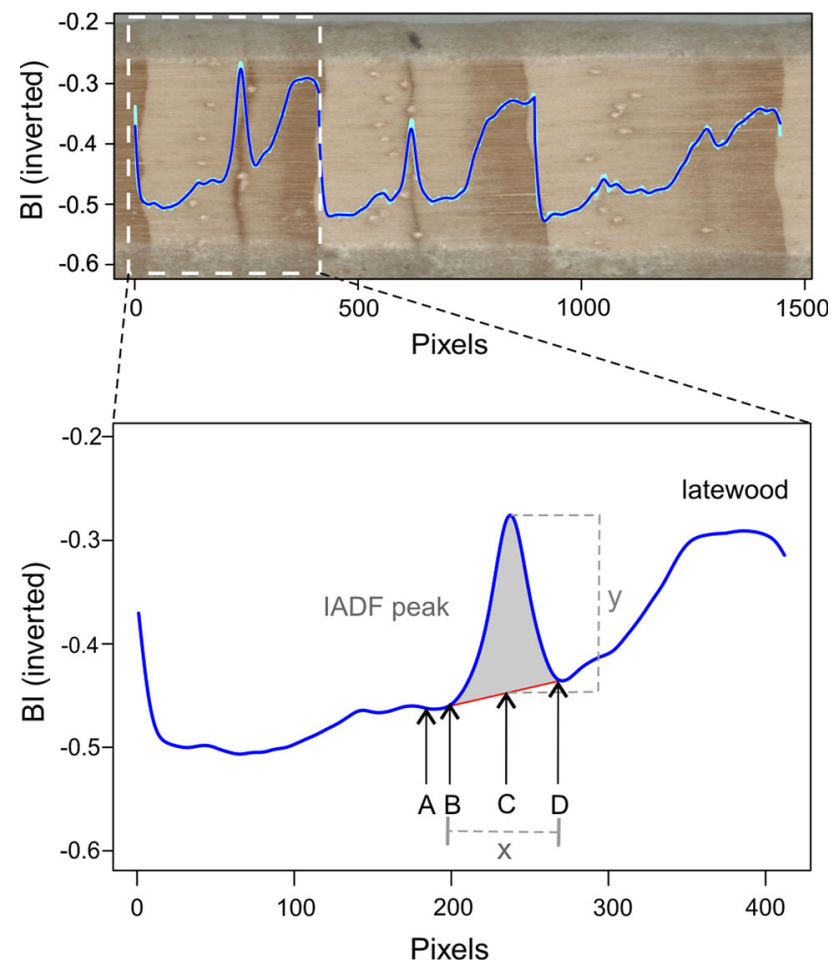

Fig. 2 Characterization of intra-annual density fluctuations (IADF) based on blue intensity (BI; light blue raw, dark blue smoothed) profiles. An automated peak detection algorithm yields the peak position $(C)$, as well as the valleys before $(A)$ and after $(D)$. A tangent from point $D$ to the preceding BI curve (red line; touching at point $B$ ) was used as a baseline for the peak width $(x)$, height $(y)$, and area (gray shade) calculation. This tangent line approximates "normal" growth when no IADF is formed

to the preceding part of the BI curve. This refines a similar approach by Gonzalez-Benecke et al. (2015), who used a horizontal line as an approximation in X-ray density profiles. Overall, the sensitivity of our IADF detection was comparable to that of the traditional visual assessment, i.e. all captured IADFs were also visible to the eye and all visible IADFs were detected from the BI profiles.

It is known that IADFs occur more frequently in larger rings and that their formation is also related to cambial tree age (e.g. Campelo et al. 2015). Such effects can bias the environmental signal in IADF records and we thus searched for temporal trends in the IADF frequency in our data using a cubic smoothing spline (Fig. S1). The occurrence of IADFs was reasonably coherent over the 1932-1995 period during which we calculated basic chronology statistics for each of the measured parameters using the dplR package in $R$ (Bunn 2008). The period after 1995 was discarded because of a significant drop in IADF frequency (and TRW) that is likely related to the "turn of the century drought" in the study area (Schwalm et al. 2012). 


\section{Climate data}

We assessed a series of climate parameters including air temperature (TMP), precipitation (PRC), vapor pressure deficit (VPD), potential evapotranspiration (PET), shortwave radiation (RAD), air pressure (PRESS), and the onset date of the NAM (publicly available from the North American Weather Service, NOAA). For TMP and PRC, daily meteorological station data were available (Table 1) and we aggregated these data to monthly means and sums, respectively. For months that contained $>20 \%$ missing values, we applied a gap-filling procedure using the closest grid cell from the CRU 3.21 gridded climatology (Hijmans et al. 2005) that we scaled to the mean and standard deviation of the monthly station time-series. In addition, we accounted for the considerable altitudinal difference between the Pinaleño site and the closest meteorological station in Safford, Arizona. For this purpose, we determined the local adiabatic lapse rate $\left(0.83{ }^{\circ} \mathrm{C} / 100 \mathrm{~m}\right)$ and PRC change with elevation $(0.37-3.84 \mathrm{~mm} / 100 \mathrm{~m}$, depending on the season) from the difference between the Palisades Ranger Station and the long-term meteorological station located in the nearby city of Tucson $(\sim 700 \mathrm{~m}$ a.s.l.). Monthly VPD for the closest grid cell was calculated from CRU 3.21 products (saturated vapor pressure minus actual vapor pressure) and PET was obtained from the same source. Monthly RAD and PRESS were extracted from the CRU/NCEP gridded climate dataset (Wei et al. 2014).

\section{Climatic drivers of radial growth and IADF formation}

Two steps of data treatment were applied to the radial growth parameters (EWW, LWW, and TRW) in preparation of the climate response analyses. In a first step, we removed the geometric age trend from all TRW, EWW, and LWW series using a cubic smoothing spline detrending with a $50 \%$ frequency cutoff response at 30 years (Cook and Peters 1997). This procedure omitted low-frequency trends from the data while preserving annual to decadal growth variability. The BI parameters showed little longterm variability and were not detrended. The second step concerned only the LWW chronologies that were positively related to the respective EWW chronologies $(r=0.55$ and 0.63 for the Santa Catalina and Pinaleño sites). This lag effect can complicate assessment of climate impacts on latewood formation (Meko and Baisan 2001). Hence, we removed the EWW influence on LWW for each measurement series by means of a linear regression model with EWW and LWW as the independent and dependent variables, respectively (Griffin et al. 2011). The residuals of this model are subsequently referred to as adjusted LWW (LWW adj; Stahle et al. 2009).
We performed three steps of analyses that investigated the response of radial growth and IADF formation to the climate parameters over the 1932-1995 period: (1) we assessed climatic differences between years with a frequent vs. rare $(<25$ and $>75 \%$ of cores) occurrence of IADFs and with an early vs. late ( $<25$ and $>75 \%$ of TRW) position of the IADF using the Wilcoxon signed rank test (some parameters showed skewed distributions; Levene's test); (2) we calculated Pearson's correlation coefficients between both radial growth and BI parameters with monthly to seasonal climate from the previous and current years. We chose six seasons that are climatologically meaningful for tree growth in the study area and represent winter (January-March), early spring (MarchApril), spring (April-May), early summer (May-June), monsoon (July-August), and post-monsoon (SeptemberOctober); (3) acknowledging the close connection between some of the assessed climate parameters, we calculated climate response functions using the bootRes package in $\mathrm{R}$ (Zang and Biondi 2013). This procedure involves a principal component analysis of the climatic predictor variables, resulting in a new orthogonal set of predictors and thereby eliminating multicollinearity issues.

\section{Results}

\section{Evaluation of radial growth and IADF parameters}

Despite the relatively small sample size, the radial growth chronologies from both sites showed strong chronology statistics with mean inter-series correlations (Rbar) between 0.4 for $\mathrm{LWW}_{\text {adj }}$ and 0.78 for TRW throughout the 1932-1995 period (Table 2). The corresponding mean sensitivities ranged between 0.355 and 0.51 . A comparison with Ponderosa pine chronologies from the international tree-ring data bank showed that the TRW chronologies from the Santa Catalina and Pinaleño Mountains are representative of a larger region across the US Southwest (Fig. S2). Nevertheless, radial growth corresponded only moderately between the two neighboring mountain ranges. The observed correlations between the detrended site chronologies were $r_{\mathrm{TRW}}=0.47, \quad r_{\mathrm{EWW}}=0.46$, $r_{\mathrm{LWW}}=0.24, r_{\mathrm{LWWadj}}=0.19$. This is indicative of different growth limitations at the two sites. Of all evaluated BI parameters, peak height, width, and area showed Rbars above the widely accepted critical correlation of $r=0.299$ over 30 years (see COFECHA; Holmes 1983). As the strength of this common signal among trees was comparable to that observed in LWW and $\mathrm{LWW}_{\text {adj }}$ (Table 2), we identified these three BI parameters as most suitable to characterize IADFs at our sites. Accordingly, we included them in the climate response analysis together with the traditional radial growth measures. 


\section{Climatic drivers of radial tree growth}

We assessed the monthly to seasonal climatic drivers of radial tree growth and found that TRW and EWW at both sites showed a similar negative response to March-April TMP and VPD (Fig. 3). This is also reflected by the negative correlation with March-May RAD and PET at the Santa Catalina site and November-May RAD and PET at the Pinaleño site (Fig. S3). While these signals emphasize the drought sensitivity of radial tree growth in the study area, we observed marked differences in the seasonality of the PRC response between the two sites. Radial tree growth at the Santa Catalina site relied strongly on spring (i.e. April) PRC, whereas radial growth at the Pinaleño site benefited most from December-March PRC. In terms of $\mathrm{LWW}_{\mathrm{adj}}$, the strongest PRC response at the Santa Catalina site occurred in mid summer (June-August), with a peak in July as suggested by the response functions (Fig. S4). The beneficial effect of the NAM is also reflected by a negative correlation with August-September RAD. In contrast, $\mathrm{LWW}_{\mathrm{adj}}$ at the Pinaleño site responded to PRC in late summer (August-September) and additionally relied on water reservoirs from the antecedent winter.

As latewood formation was related to summer PRC at both sites, we tested for impacts of the NAM onset date on $\mathrm{LWW}_{\mathrm{adj}}$. The average date of the first monsoon rain is July 3, as recorded in the nearby city of Tucson between 1949 and 2015 (North American Weather Service, NOAA). We found a significant relationship between the NAM onset date and $\mathrm{LWW}_{\text {adj }}$ for the Santa Catalina site, but not for the Pinaleño site (Fig. 4).

\section{Climatic drivers of IADF frequency, position, and characteristics}

We compared the monthly and seasonal climate conditions in years with frequent and rare ( $>75 \mathrm{vs} .<25 \%$ of samples) IADF formation. At the Santa Catalina site, significant differences at $P<0.05$ emerged with respect to VPD and PET in March and PRC in March-April (see Fig. 5a for seasonal and Fig. S5a for monthly results), indicating that a humid early spring favors IADF formation. In addition, cool and humid post-monsoon conditions (significant for TMP, PRC, VPD, and PET) promoted IADFs. At the Pinaleño site, March-April TMP, as well as April-May VPD and PET were significantly higher in years with frequent IADF occurrence, evidencing their sensitivity to spring and pre-summer drought. Reduced late-season VPD and PET also favored IADF formation at this site.

Similar to the above analysis, we compared years that fell into the first and fourth quartiles of the observed IADF positions (see Fig. 5b for seasonal and Fig. S5b for monthly results). At the Santa Catalina site, a late IADF position was favored by humid winter and spring conditions (significant at $P<0.05$ for January-May PRC and March-May PET) and additionally by high July-August VPD and PET, indicating that a weak monsoon leads to IADF formation. At the Pinaleño site, a humid winter and reduced evaporative demand in spring and early summer led to a late IADF position (significant for February PRC and March-June VPD). In addition, cool conditions in September-October favored a late position. Overall, IADFs occurred significantly earlier $(P<0.001$, two-tailed Student's $t$ test $)$ in the

Table 2 Mean inter-series correlation (Rbar) of the radial growth and blue intensity (BI) parameters

\begin{tabular}{|c|c|c|c|c|c|c|}
\hline & \multicolumn{3}{|c|}{ Santa Catalina Mountains } & \multicolumn{3}{|c|}{ Pinaleño Mountains } \\
\hline & $1935-1964$ & $1950-1979$ & 1967-1994 & 1935-1964 & 1950-1979 & 1967-1994 \\
\hline TRW & 0.49 & 0.63 & 0.72 & 0.78 & 0.77 & 0.6 \\
\hline EWW & 0.54 & 0.6 & 0.7 & 0.75 & 0.73 & 0.56 \\
\hline LWW & 0.41 & 0.45 & 0.41 & 0.64 & 0.65 & 0.56 \\
\hline $\mathrm{LWW}_{\text {adj }}$ & 0.48 & 0.44 & 0.4 & 0.56 & 0.46 & 0.47 \\
\hline BI peak height & 0.38 & 0.4 & 0.45 & 0.61 & 0.45 & 0.54 \\
\hline BI peak width (abs.) & 0.2 & 0.32 & 0.43 & 0.42 & 0.37 & 0.34 \\
\hline BI peak width ( $\%$ of TRW) & 0.19 & 0.14 & 0.36 & 0.46 & 0.34 & 0.35 \\
\hline BI peak position (abs.) & 0.25 & 0.38 & 0.47 & 0.35 & 0.25 & 0.24 \\
\hline BI peak position ( $\%$ of TRW) & 0.09 & 0.08 & 0.2 & 0.32 & 0.22 & 0.24 \\
\hline BI peak area & 0.37 & 0.31 & 0.42 & 0.45 & 0.41 & 0.44 \\
\hline Minimum BI & 0.01 & 0.03 & 0.28 & 0.24 & 0.26 & 0.23 \\
\hline Maximum BI & -0.17 & 0.03 & 0.15 & 0.38 & 0.32 & 0.22 \\
\hline
\end{tabular}

Values that exceed the critical Rbar of 0.299 (corresponding to the COFECHA default) are marked in bold

$T R W$ tree-ring width, $E W W$ earlywood width, $L W W$ latewood width, $L W W_{\text {adj }}$ adjusted latewood width 
(a)

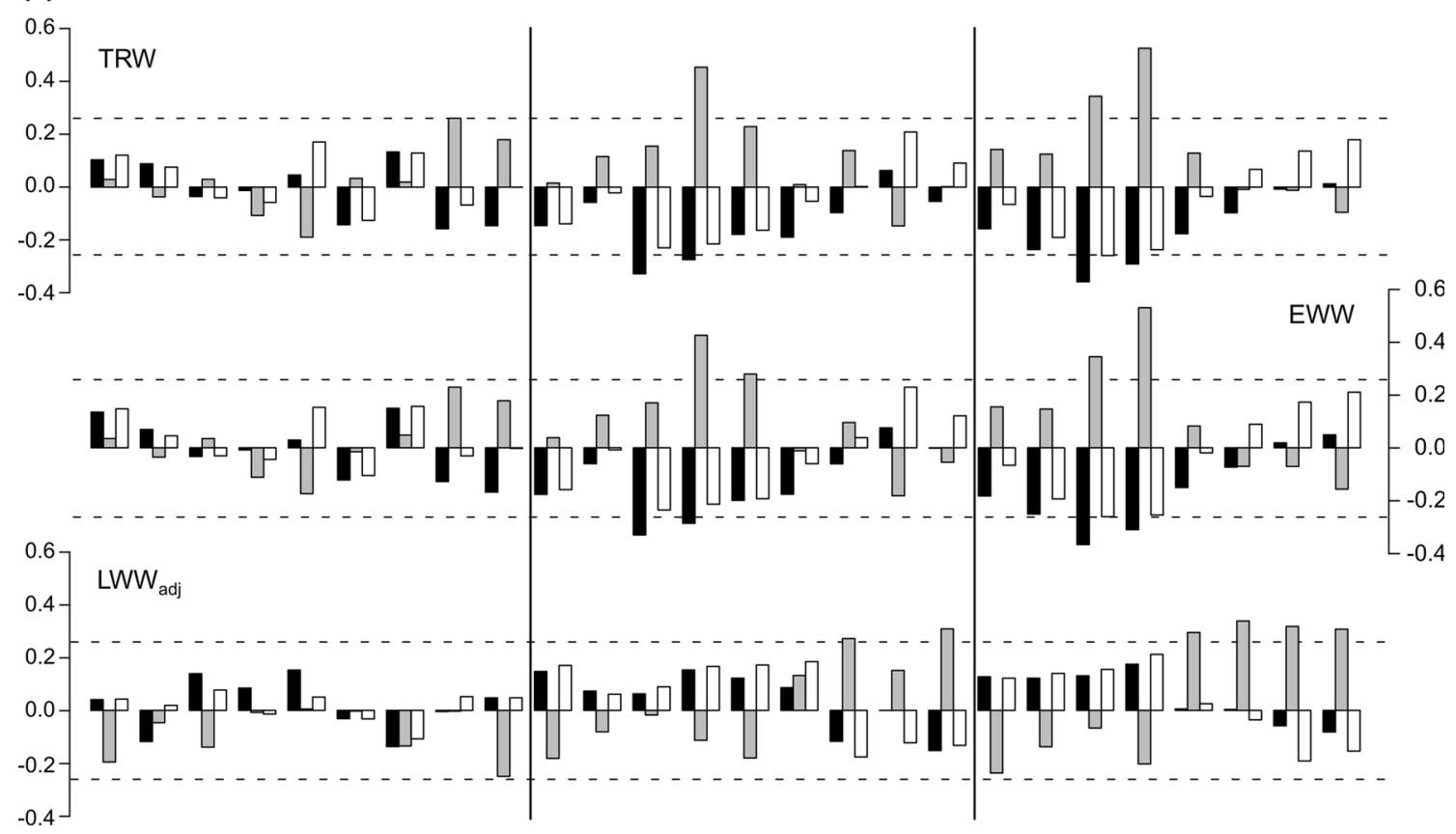

(b)

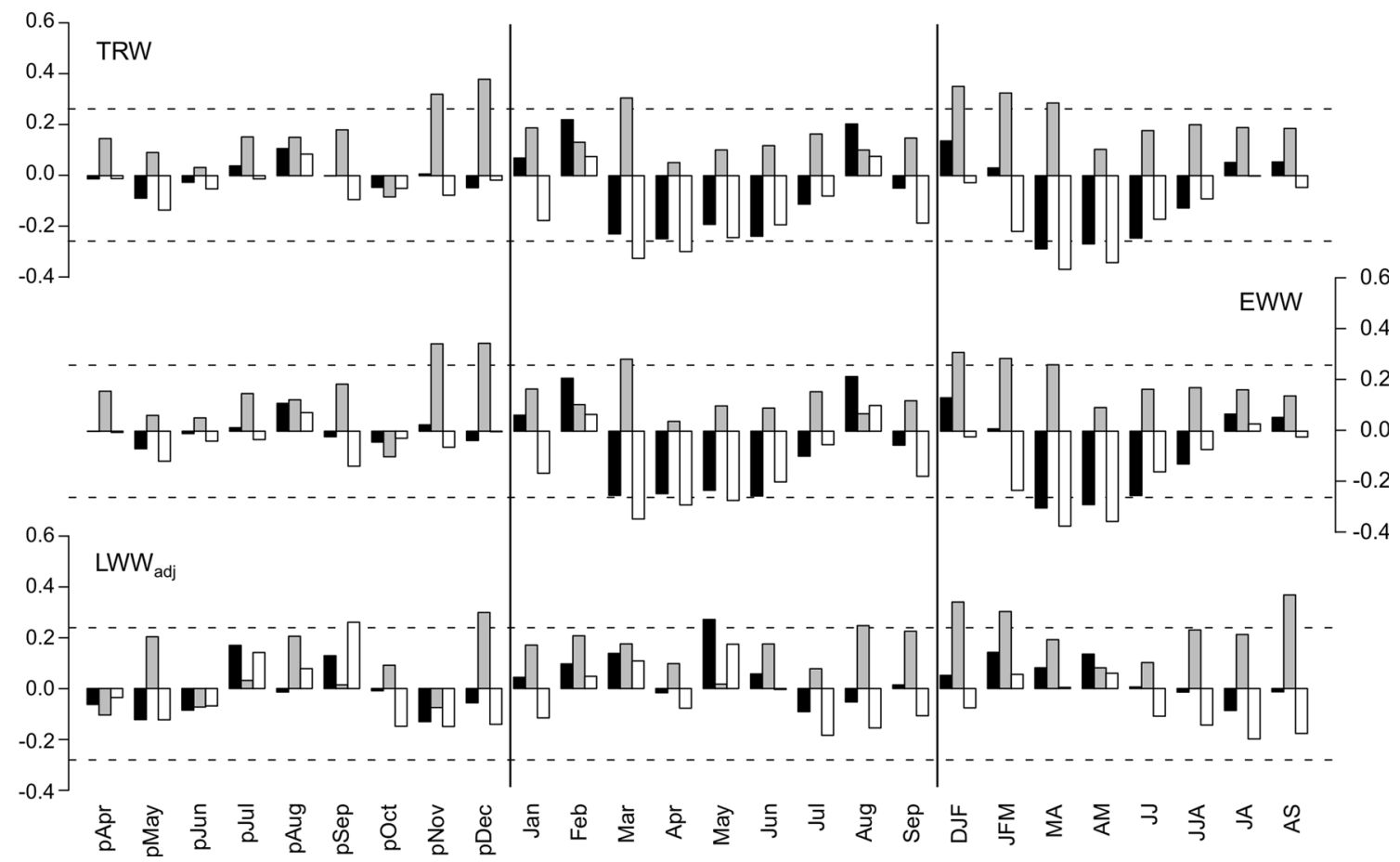

Fig. 3 Monthly and seasonal correlations of radial tree growth with temperature (black), precipitation (gray), and vapor pressure deficit (white) at the Santa Catalina (a) and Pinaleño (b) sites. TRW tree-ring

annual growth ring at the Santa Catalina site compared to the Pinaleño site with the average positions at 52 and $59 \%$ of TRW, respectively (Fig. 6).

Last, we correlated the size and intensity of the IADFs (i.e. BI peak height, width, and area) with seasonal climate width, $E W W$ earlywood width, $L W W_{\text {adj }}$ adjusted latewood width, $p$ (month) previous year. Horizontal dashed lines mark the critical value for significant correlations at $P<0.05$

conditions. This analysis we performed separately for years with early and late IADF positions, the former of which generally showed stronger climate signals (Fig. 7). Drought conditions in May-June triggered an intense earlyposition IADF at the Santa Catalina site $(P<0.05$ for BI 


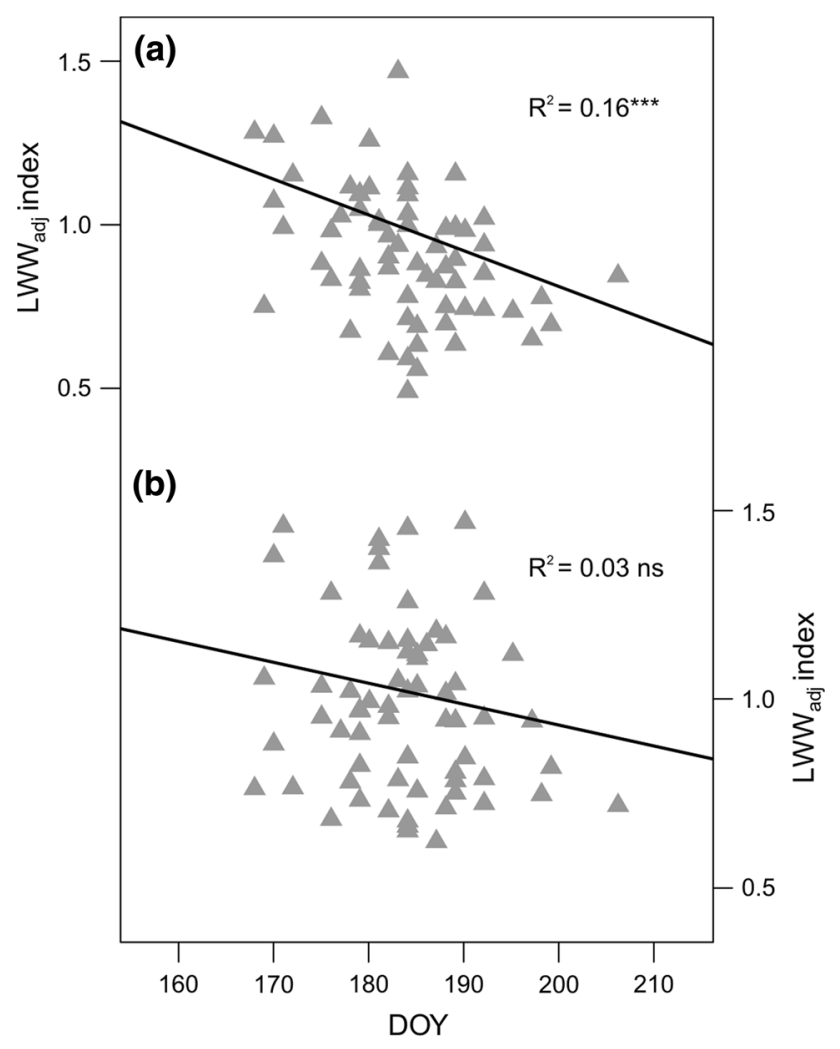

Fig. 4 Relationship between adjusted latewood width (LWW $\left.{ }_{\text {adj }}\right)$ and the day of the year (DOY) of the summer monsoon onset at the Santa Catalina (a) and the Pinaleño (b) sites. $* * * P<0.001 ; n s$ not significant

peak height vs. VPD and PET), but not necessarily a wider one (correlations for BI peak width were not significant). By contrast, increased May-June PRC tended to favor wider IADFs. A hot summer and early autumn led to narrow IADFs. In the case of a later position, narrow IADFs were also associated with summer heat $(P<0.05)$ and to a lesser extent with low April-May PRC (not significant). At the Pinaleño site, low PRC and high PET in winter caused intense early-position IADFs $(P<0.05)$. Contrarily, hot and dry conditions in September-October led to less pronounced IADFs. Narrow late-position IADFs were associated with dry conditions towards the end of the growing season $(P<0.05$ for September-October VPD and PET).

\section{Discussion and conclusions}

\section{A novel application of the blue intensity methodology}

We explored the use of blue intensity parameters to assess IADFs in annual growth rings, build robust chronologies, and identify their climatic drivers. The automated detection procedure that we developed proved reliable to isolate IADFs from the pixel-based BI profiles and thus offers an efficient and objective alternative to visual identification. Out of nine investigated BI parameters, peak height, width, and area showed the strongest common signal among trees as expressed by the Rbar. This common signal was weaker than those observed in EWW and TRW-which are characteristically high at sites from the US Southwest (Brice et al. 2013) —but comparable to that found in $\mathrm{LWW}_{\mathrm{adj}}$. As the latter parameter has been used for dendroclimatological purposes in this region (e.g. Griffin et al. 2013), we consider the three BI parameters to also be useful for dendroclimatological applications in the NAM domain. Future development of intra-annual BI chronologies in other species and regions will shed light on their applicability at a larger spatial scale and under different climate regimes.

Adding IADF characterization to the existing set of BI applications extends the scope of this relatively young methodology beyond its original purpose as a surrogate for the cost- and labor-intensive X-ray density measurements (McCarroll et al. 2002; Campbell et al. 2007). IADFs are the result of complex interactions between tree physiology and climate that drive xylogenesis (Cuny et al. 2014; Babst et al. 2014; Vieira et al. 2014); detailed information on their occurrence and shape can thus contribute to better understanding of these interactions. However, it should be emphasized that the successful application of BI parameters at larger scales will depend on standardized protocols to ensure the compatibility of results. We relied on the methodology proposed by Campbell et al. (2011), who used the WinDendro software for simultaneous characterization of radial growth and BI. This approach-with the modification for pixel-based BI output-is straightforward in its implementation, but not free of potential biases. For instance, the surface preparation of the wood samples can affect wavelength-dependent photon reflectance and hence the resulting BI values (Babst et al. 2009), as do color changes associated with the pronounced heartwood-sapwood transition in some species (Björklund et al. 2014); however, this was not the case in our Ponderosa pine samples. While our IADF peak characterization is ringspecific and should thus be rather insensitive to changes in the magnitude of the BI values throughout an increment core, such biases cannot be fully excluded.

\section{Differing seasonality at the two study sites}

We observed pronounced differences in radial growth and the seasonality of its climate response between the two study sites, despite similar mean tree age, site conditions, and the relatively short horizontal and altitudinal distance separating sites. Interestingly, these differences concern mostly the water availability (winter vs. spring PRC and 
(a)

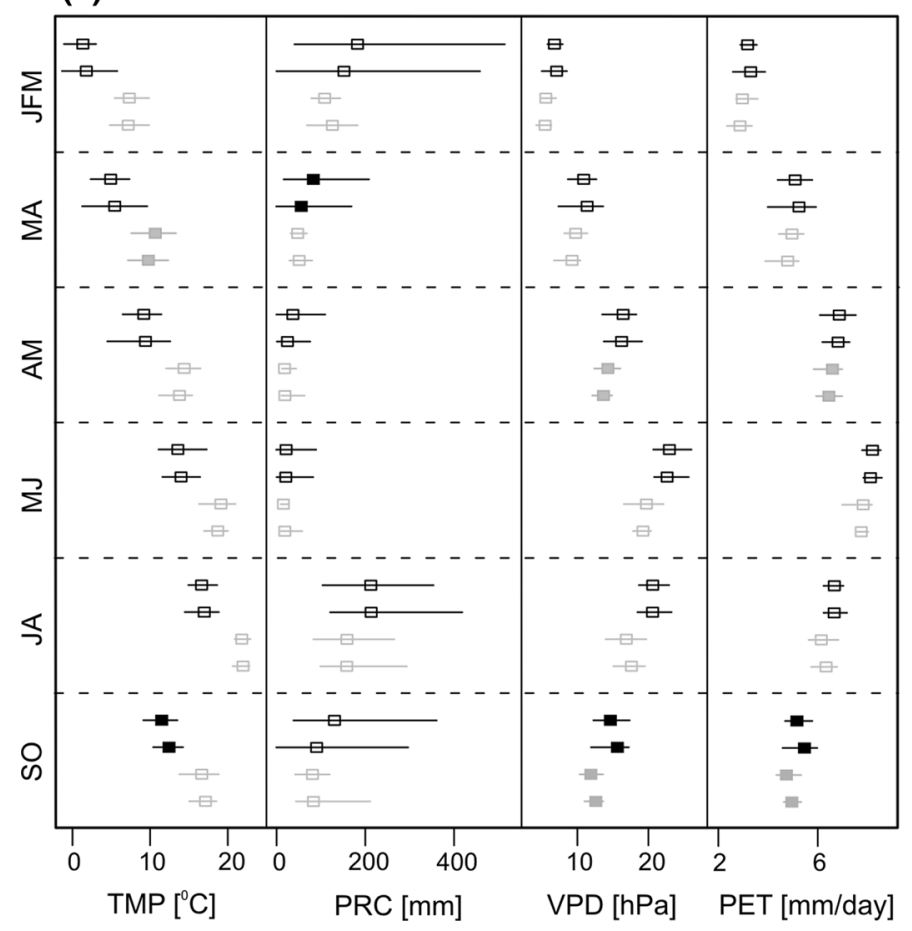

(b)

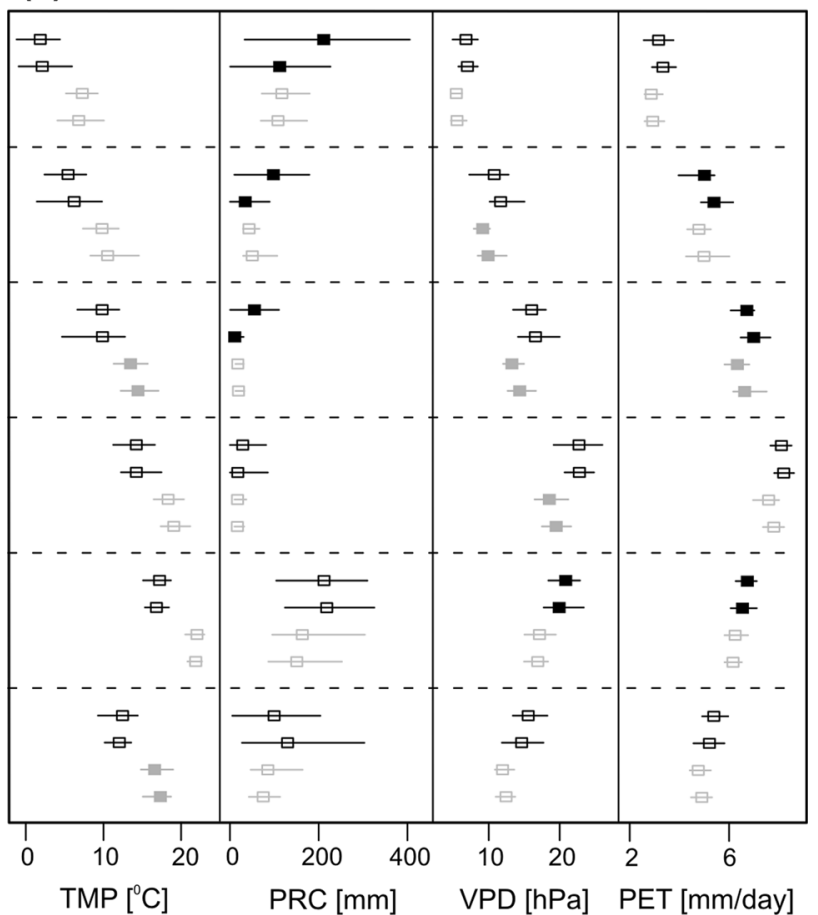

Fig. 5 Mean (rectangles) and range of seasonal climate conditions at the Santa Catalina (black) and Pinaleño (gray) sites leading to frequent ( $>75 \%$ of samples; higher lines) or rare ( $<25 \%$ of samples; lower lines) intra-annual density fluctuation (IADF) occurrence is shown in a. The corresponding results for late $(>75 \%$ of TRW;

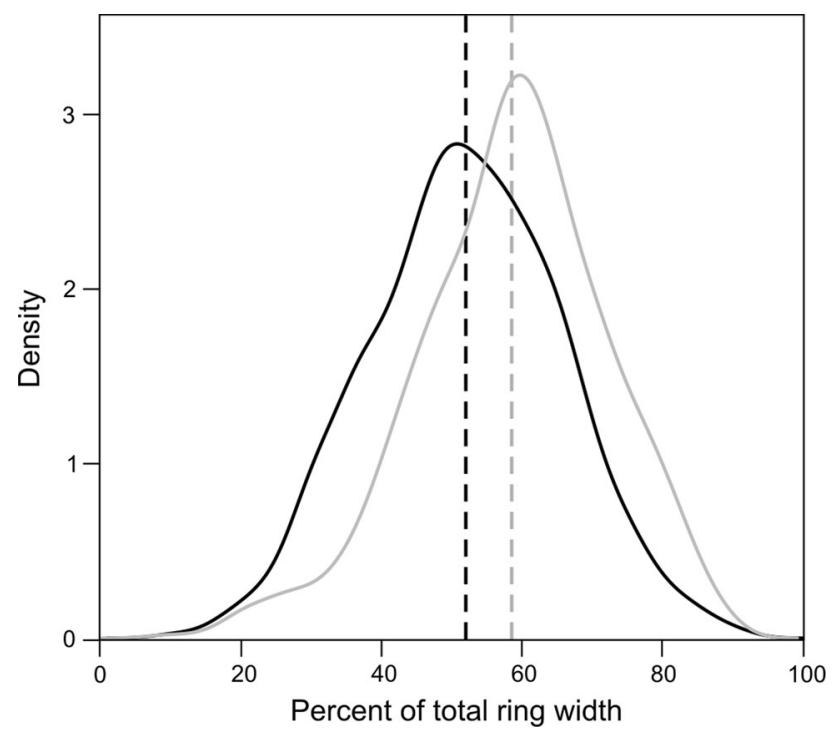

Fig. 6 Probability density functions of the intra-annual density fluctuation positions at the Santa Catalina (black) and Pinaleño (gray) sites. Dashed lines indicate the mean position at each site

early vs. late summer PRC), but to a lesser extent the water demand (comparable VPD and PET signals). As winter snow cover is highly heterogeneous in its spatiotemporal higher lines) or early ( $<25 \%$ of TRW; lower lines) IADF positions within the annual growth rings are displayed in b. Full rectangles indicate significant differences at $P<0.05$. TMP temperature, $P R C$ precipitation, $V P D$ vapor pressure deficit, $P E T$ potential evapotranspiration

distribution in the study area (Palisade Ranger Station meteorological station, data not shown), it is likely that the timing of the growth onset drives the divergent PRC response. At two Ponderosa pine sites located at comparable elevations (2000 and $2310 \mathrm{~m}$ a.s.1.) in the Bandelier National Monument (New Mexico, USA), dendrometer band data collected between 1992 and 2012 showed that the start of the growing season at the higher site lags behind that of the lower site by roughly 3 weeks (mid April vs. early to mid May; McDowell et al. 2010 and C. Allen unpublished data). Accordingly, the growth onset at the Pinaleño site occurs at the very beginning of the presummer drought period and trees benefit from soil water replenishment during the preceding winter months. By contrast, tree growth at the Santa Catalina site starts during the core drought period, which increases their dependence on spring (i.e. April) PRC. The rather shallow soil at this site ( $\sim 0.5 \mathrm{~m}$; field observation) may additionally accentuate water limitation (Franklin et al. 2012).

The dominance of water availability over stem growth phenology was confirmed by the climate signals retained in the IADF parameters, but - analogous to radial growthwith a different seasonality in the early growing season. Both IADF occurrence and position at the Santa Catalina 
Fig. 7 Correlations between intra-annual density fluctuation characteristics (i.e. blue intensity peak height, width, and area) with seasonal climate conditions. Results for the Santa Catalina (a) and Pinaleño (b) sites are shown separately for early (left columns) and late (right columns) intra-annual density fluctuation positions within the annual growth rings. Significant seasons at $P<0.05$ are indicated by black frames. $T M P$ temperature, $P R C$ precipitation, $V P D$ vapor pressure deficit, $P E T$ potential evapotranspiration (a)

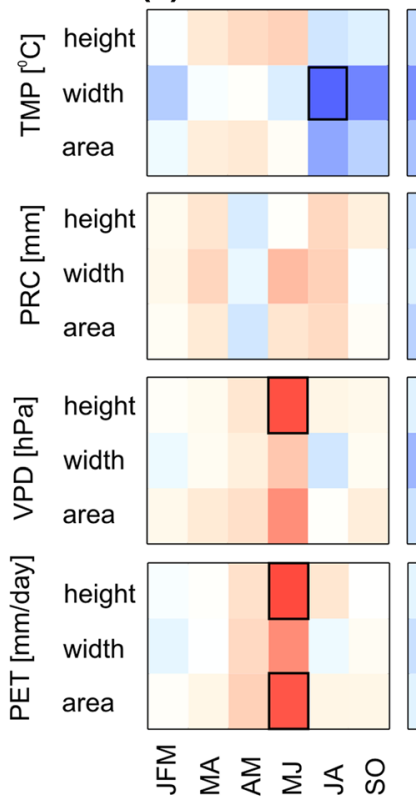

(b)
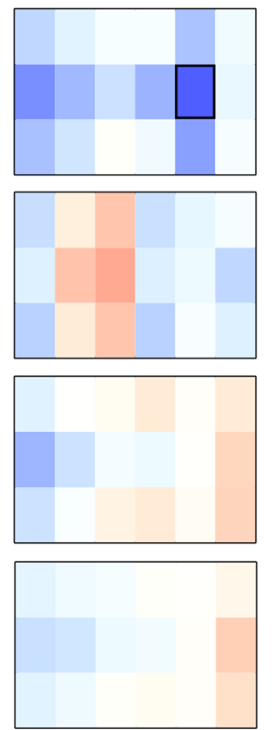

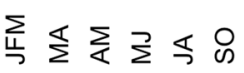
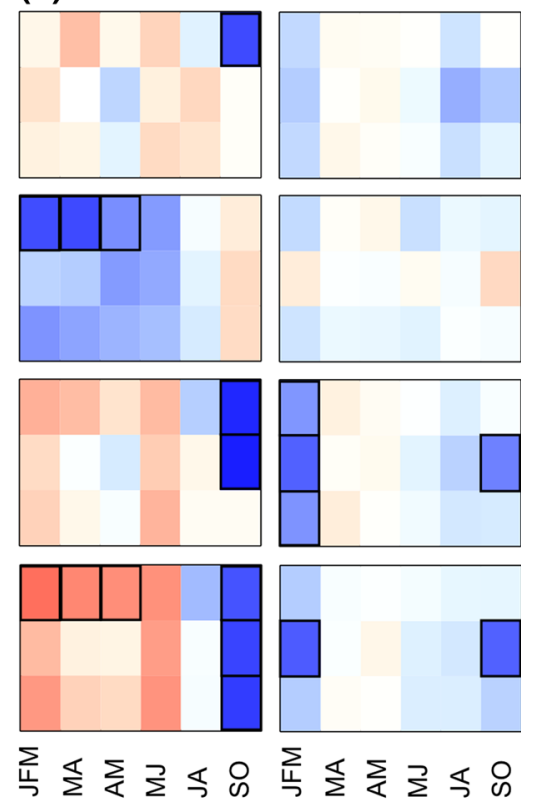

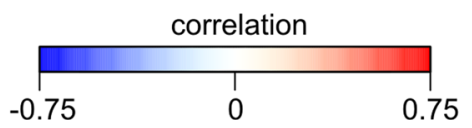

site were positively related to spring PRC, whereas occurrence was positively related to spring VPD and PET at the Pinaleño site (Fig. 5a). At the same time, May-June drought caused intense early-position IADFs at both sites (Fig. 7). This indicates that the regular pre-summer drought period in the study area indeed leads to stomatal closure, but that trees at the higher site only assume enough radial growth to form an IADF, if the preceding months were sufficiently humid. Hence, the onset of the growing season appears to be both water and energy limited at the higher-elevation site, whereas it is mostly energy limited at the lower site. Similarly, a late IADF position was associated with a weak monsoon at the Santa Catalina site and with favorable growth conditions in the post-monsoon season at both sites. In addition, reduced evaporative demand in September-October leads to a wider IADF at the Pinaleño site. These findings suggest that the climate towards the end of the growing season needs to allow for enough radial growth to distinguish IADFs from the actual latewood. The monsoon rain is of much greater importance for the Santa Catalina site compared to the Pinaleño site because the earlier termination of winter dormancy at the latter site allows trees to make more use of winter PRC. This is also indicated by the observed relationship with the NAM onset date at the Santa Catalina site and by the significantly larger fraction of post-IADF growth (Fig. 6) that is considered to be driven by the NAM (Griffin et al. 2011, 2013). Overall, our findings emphasize that seasonal water limitation is a major driver of growth phenology in Ponderosa pine from the US Southwest at the beginning, throughout, and at the end of the growing season.

\section{Perspectives}

Water limitation of tree growth in the US Southwest is projected to increase dramatically over the coming decades (Williams et al. 2013), thereby exacerbating the vulnerability of forests to disturbance regimes (McDowell et al. 2015) and ultimately biome shifts (Cheaib et al. 2012; Choat et al. 2012; McDowell and Allen 2015). Mechanisms of tree mortality under severe drought are being intensely studied and current understanding is that hydraulic failure, as well as insufficient uptake, transport, and remobilization of carbohydrates can contribute to forest dieback (Sevanto et al. 2014). While trees that are adapted to arid environments may quickly recover from short-term drought spells (Tatarinov et al. 2015), the steady temperature rise and associated increase in atmospheric evaporative demand is expected to cause large-scale forest mortality by the end of the twenty-first century (McDowell et al. 2015). Recent observations have already indicated an increasing number of missing rings in tree-ring records from forests growing near the dry limit of their distribution range and have additionally observed increased mortality rates towards the present (Liang et al. 2016). While we did not observe such trends in our data, we found a considerable number of 
missing rings during the "turn of the century drought" in the study area (Schwalm et al. 2012), evidencing the susceptibility of Ponderosa pine forests to extreme drought. The mean annual TMP at the Pinaleño sites is $3.3^{\circ} \mathrm{C}$ higher than at the Santa Catalina site-a temperature shift that is expected to occur by approximately 2070 in this area (CMIP5 ensemble mean). Assuming that the climate signals that we observed herein remain valid for the twenty-first century (which may not necessarily be the case; Gustafson 2013), the importance of the NAM as a moisture source in the study area will further increase. This has direct societal and economic consequences and additionally affects the terrestrial carbon balance at regional (Schwalm et al. 2012) and global (Ahlström et al. 2015) scales. Yet, part of this effect could be offset by an earlier start of the growing season that would allow trees at higher elevation to make more use of PRC that fell during the winter months. In addition, an earlier onset of the growing season is associated with a larger number of xylem cells produced and a prolonged duration of wood formation (Lupi et al. 2010; Rossi et al. 2014). With the timing of the growing season being both dynamic and uncertain (Richardson et al. 2013), we anticipate that a combination of empirical and computational approaches will be most promising to shed light on these issues. For instance, Touchan et al. (2012) successfully modeled intra-annual pine growth in a Mediterranean environment. The combination of this and other data streams, for example, stable isotope measurements of the IADF area (Battipaglia et al. 2010, 2013) with radial growth and BI parameters can help elucidate the links between stem and canopy processes under changing environmental conditions. Thus, our newly developed BI parameters may also find application in ecophysiological studies aimed at a better understanding of seasonal water and carbon cycling in semi-arid environments.

Author contribution statement FB designed and led the study with critical input from WEW and RKM. LW and WEW performed the measurements. PS and SB contributed to data analyses and interpretation. All authors contributed to the writing process.

Acknowledgments We thank Rafał Kostecki, Alicja Babst-Kostecka, Valerie Trouet, Jesper Björklund, Kristina Seftigen, and David Frank for their input and the fruitful discussions. FB acknowledges funding from the Swiss National Science Foundation (Grant P300P2_154543). Supported by a grant from the Macrosystems program in the Emerging Frontiers section of the US National Science Foundation (Award \#1065790).

\section{Compliance with ethical standards}

Conflict of interest The authors declare that they have no conflict of interest.

\section{References}

Ahlström A, Raupach MR, Schurgers G et al (2015) The dominant role of semi-arid ecosystems in the trend and variability of the land $\mathrm{CO}_{2}$ sink. Science 348:895-899

Babst F, Frank D, Büntgen U, Nievergelt D, Esper J (2009) Effect of sample preparation and scanning resolution on the blue reflectance of Picea abies. TRACE Proc 7:188-195

Babst F, Alexander MR, Szejner P et al (2014) A tree-ring perspective on the terrestrial carbon cycle. Oecologia 176:307-322

Battipaglia G, DeMicco V, Brand WA, Linke P, Aronne G, Saurer M, Cherubini P (2010) Variations of vessel diameter and 13C in false rings of Arbutus unedo L. reflect different environmental conditions. New Phytol 188:1099-1112

Battipaglia G, DeMicco V, Brand WA, Saurer M, Aronne G, Linke P, Cherubini P (2013) Drought impact on water-use efficiency and intra-annual density fluctuations in Erica arborea on Elba (Italy). Plant Cell Environ 37:382-391

Björklund JA, Gunnarson BE, Seftigen K, Esper J, Linderholm HE (2014) Blue intensity and density from northern Fennoscandian tree rings, exploring the potential to improve summer temperature reconstructions with earlywood information. Clim Past 10:877-885

Blessing CH, Werner RA, Siegwolf R, Buchmann N (2015) Allocation dynamics of recently fixed carbon in beech saplings in response to increased temperatures and drought. Tree Physiol 35:585-598

Bogino S, Bravo F (2009) Climate and intraannual density fluctuations in Pinus pinaster subsp. mesogeensis in Spanish woodlands. Can J For Res 39:1557-1565

Brice B, Lorion KK, Griffin D et al (2013) Signal strength in subannual tree-ring chronologies from Pinus ponderosa in Northwestern New Mexico. Tree Ring Res 69:81-86

Bunn AG (2008) A dendrochronology program library in R (dplR). Dendrochronologia 26:115-124

Camarero JJ, Olano JM, Parras A (2010) Plastic bimodal xylogenesis in conifers from continental Mediterranean climates. New Phytol 185:471-480

Campbell R, McCarroll D, Loader NJ, Grudd H, Robertson I, Jalkanen R (2007) Blue intensity in Pinus sylvestris tree rings: developing a new palaeoclimate proxy. Holocene 17:821-828

Campbell R, McCarroll D, Robertson I, Loader NJ, Grudd H, Gunnarson B (2011) Blue intensity in Pinus sylvestris tree rings: a manual for a new palaeoclimate proxy. Tree Ring Res $67: 127-134$

Campelo F, Nabais C, Freitas H, Gutierrez E (2007) Climatic significance of tree-ring width and intra-annual density fluctuations in Pinus pinea from a dry Mediterranean area in Portugal. Ann Forest Sci 64:229-238

Campelo F, Vieira J, Battipaglia G, de Luis M, Nabais C, Freitas H, Cherubini P (2015) Which matters most for the formation of intra-annual density fluctuations in Pinus pinaster: age or size? Trees 29:237-245

Carvalho A, Nabais C, Vieira J, Rossi S, Campelo F (2015) Plastic response of tracheids in Pinus pinaster in a water-limited environment: adjusting lumen size instead of wall thickness. PLoS One 10:0136305

Cheaib A, Badeau V, Boe J (2012) Climate change impacts on tree ranges: model intercomparison facilitates understanding and quantification of uncertainty. Ecol Lett 15:533-544

Choat B, Jansen S, Brodribb TJ et al (2012) Global convergence in the vulnerability of forests to drought. Nature 491:752-755 
Cook ER, Peters K (1997) Calculating unbiased tree-ring indices for the study of climatic and environmental change. Holocene 7:361-370

Copenheaver CA, Pokorski EA, Currie JE, Abrams MD (2006) Causation of false ring formation in Pinus banksiana: a comparison of age, canopy class, climate and growth rate. For Ecol Manag 236:348-355

Cuny H, Rathgeber CBK, Frank DC, Fonti P, Fournier M (2014) Kinetics of tracheid development explain conifer tree-ring structure. New Phytol 203:1231-1241

Cuny H, Rathgeber CBK, Frank DC et al (2015) Woody biomass production lags stem-girth increase by over one month in coniferous forests. Nat Plants. doi:10.1038/NPLANTS.2015.160

De Luis M, Novak K, Raventos J, Gricar J, Prislan P, Cufar K (2011) Climate factors promoting intra-annual density fluctuations in Aleppo pine (Pinus halepensis) from semiarid sites. Dendrochronologia 29:163-169

De Micco V, Battipaglia G, Brand WA, Linke P, Saurer M, Aronne G, Cherubini P (2012) Discrete versus continuous analysis of anatomical and $13 \mathrm{C}$ variability in tree rings with intra-annual density fluctuations. Trees 26:513-524

De Micco V, Battipaglia G, Cherubini P, Aronne G (2013) Comparing methods to analyse anatomical features of tree rings with and without intra-annual density fluctuations (IADFs). Dendrochronologia 32:1-6

De Soto L, De la Cruz M, Fonti P (2011) Intra-annual patterns of tracheid size in the Mediterranean tree Juniperus thurifera as an indicator of seasonal water stress. Can J For Res 41:1280-1294

Die AD, Kitin P, N'Guessan-Kouame F, Van den Bulcke J, Van Acker J, Beeckman H (2012) Fluctuations in cambial activity in relation to precipitation result in annual rings and intra-annual growth zones of xylem and phloem in teak (Tectona grandis) in Ivory Coast. Ann Bot 110:861-873

Eschbach W, Nogler P, Schär E, Schweingruber FH (1995) Technical advances in the radiodensitometrical determination of wood density. Dendrochronologia 13:155-168

Frank DC, Poulter B, Saurer M et al (2015) Water-use efficiency and transportation across European forests during the Anthropocene. Nat Clim Change 5:579-583

Franklin O, Johansson J, Dewar RC et al (2012) Modeling carbon allocation in trees: a search for principles. Tree Physiol 32:648-666

Franks PJ, Adams MA, Amthor JS et al (2013) Sensitivity of plants to changing atmospheric $\mathrm{CO}_{2}$ concentration: from the geological past to the next century. New Phytol 197:1077-1094

Gonzalez-Benecke CA, Rivieros-Walker AJ, Martin TA, Peter GF (2015) Automated quantification of intra-annual density fluctuations using microdensity profiles of mature Pinus taeda in replicated irrigation experiment. Trees 29:185-197

Griffin D, Meko DM, Touchan R, Leavitt S, Woodhouse CA (2011) Latewood chronology development for summer moisture reconstruction in the US Southwest. Tree Ring Res 67:87-101

Griffin D, Woodhouse CA, Meko DM et al (2013) North American monsoon precipitation reconstructed from tree-ring latewood. Geophys Res Lett 40:954-958

Gustafson EJ (2013) When relationships estimated in the past cannot be used to predict the future: using mechanistic models to predict landscape ecological dynamics in a changing world. Landsc Ecol 28:1429-1437

Higgins RW, Shi W (2001) Intercomparison of the principal modes of interannual and intraseasonal variability of the North American Monsoon System. J Clim 14:403-417

Hijmans RJ, Cameron SE, Parra JL, Jones PG, Jarvis A (2005) Very high resolution interpolated climate surfaces for global land areas. Int J Climatol 25:1965-1978
Holmes RL (1983) Computer-assisted quality control in treering dating and measurement. Tree Ring Bull 43:69-78

Leavitt S, Wright WE, Long A (2002) Spatial expression of ENSO, drought, and summer monsoon in seasonal $13 \mathrm{C}$ of ponderosa pine tree rings in southern Arizona and New Mexico. J Geophys Res 107:3-10

Liang E, Leuschner C, Dulamsuren C, Wagner B, Hauck M (2016) Global warming-related tree growth decline and mortality on the north-eastern Tibetan plateau. Clim Change 134:163-176

Lin YS, Medlyn BE, Duursma RA et al (2015) Optimal stomatal behavior around the world. Nat Clim Change 5:459-464

Lupi C, Morin H, Deslauriers A, Rossi S (2010) Xylem phenology and wood production: resolving the chicken-or-egg dilemma. Plant Cell Environ 33:1721-1730

McCarroll D, Pettigrew E, Luckman A (2002) Blue reflectance provides a surrogate for latewood density of high-latitude pine tree rings. Arct Antarct Alp Res 34:450-453

McDowell NG, Allen CD (2015) Darcy's law predicts widespread forest mortality under climate warming. Nat Clim Change 5:669-672

McDowell NG, Allen CD, Marshall L (2010) Growth, carbon-isotope discrimination, and drought-associated mortality across a Pinus ponderosa elevational transect. Global Change Biol 16:399-415

McDowell NG, Beerling DJ, Breshears DD, Fisher RA, Raffa KF, Stitt M (2011) The interdependence of mechanisms underlying climate-driven vegetation mortality. Trends Ecol Evol 26:523-532

McDowell NG, Williams AP, Xu C et al (2015) Multi-scale predictions of massive conifer mortality due to chronic temperature rise. Nat Clim Change. doi:10.1038/NCLIMATE2873

Meko DM, Baisan CH (2001) Pilot study of latewood-width of conifers as an indicator of variability of summer rainfall in the North American monsoon region. Int J Climatol 21:697-708

Nabais C, Campelo F, Vieira J, Cherubini P (2014) Climatic signals of tree-ring width and intra-annual density fluctuations in Pinus pinea and Pinus pinaster along a latitudinal gradient in Portugal. Forestry 87:598-605

Novak K, Saz Sanches MA, Cufar K, Raventos J, de Luis M (2013) Age, climate and intra-annual density fluctuations in Pinus halepensis in Spain. IAWA Journal 34:459-474

Olivar J, Bogino S, Spiecker H, Bravo F (2012) Climate impact on growth dynamic and intra-annual density fluctuations in Aleppo pine (Pinus halepensis) trees of different crown classes. Dendrochronologia 30:35-47

Ren P, Rossi S, Gricar J, Liang E, Cufar K (2015) Is precipitation a trigger for the onset of xylogenesis in Juniperus przewalskii on the north-eastern Tibetan Plateau? Ann Bot 115:629-639

Richardson AD, Keenan TF, Migliavacca M, Ryu Y, Sonnentag O, Toomey M (2013) Climate change, phenology, and phenological control of vegetation feedbacks to the climate system. Agric For Meteorol 169:156-173

Rossi S, Girard MJ, Morin H (2014) Lengthening of the duration of xylogenesis engenders disproportionate increases in xylem production. Global Change Biol 20:2261-2271

Sala A, Piper F, Hoch G (2010) Physiological mechanisms of drought-induced tree mortality are far from being resolved. New Phytol 186:274-281

Schwalm C, Williams CA, Schaefer K et al (2012) Reduction in carbon uptake during turn of the century drought in western North America. Nat Geosci 5:551-556

Schweingruber FH (1983) Der Jahrring. Haupt Verlag, Bern

Sevanto S, Dickman T (2015) Where does the carbon go? Plant carbon allocation under climate change. Tree Physiol 35:581-584 
Sevanto S, McDowell N, Dickman T, Pangle R, Pockman W (2014) How do trees die? A test of the hydraulic failure and carbon starvation hypotheses. Plant Cell Environ 37:153-161

Stahle DW, Cleaveland MK, Grissino-Mayer HD, Griffin RD, Fye FK, Therrell MD, Burnette DJ, Meko DM, Villanueva Diaz J (2009) Cool- and warm-season precipitation reconstructions over Western New Mexico. J Clim 22:3729-3750

Szejner P (2011) Tropical dendrochronology: exploring tree-rings of Pinus oocarpa in eastern Guatemala. Master Thesis, GeorgAugust Universität, Göttingen

Tatarinov F, Rotenberg E, Masyek K, Ogee J, Klein T, Yakir D (2015) Resilience to seasonal heat wave episodes in a Mediterranean pine forest. New Phytol. doi:10.1111/nph.13791

Touchan R, Shishov VV, Meko DM, Nouiri I, Grachev A (2012) Process based model sheds light on climate sensitivity of Mediterranean tree-ring width. Biogeosciences 9:965-972

Venegas-Gonzalez A, von Arx G, Perez Chagas M, Filho MT (2015) Plasticity in xylem anatomical traits of two tropical species in response to intra-seasonal climate variability. Trees Struct Funct 29:423-435

Vieira J, Campelo F, Nabais C (2009) Age-dependent responses of tree-ring growth and intra-annual density fluctuations of Pinus pinaster to Mediterranean climate. Trees Struct Funct 23:257-265

Vieira J, Campelo F, Nabais C (2010) Intra-annual density fluctuations of Pinus pinaster are a record of climatic changes in the western Mediterranean region. Can J For Res 40:1567-1575
Vieira J, Rossi S, Campelo F, Freitas H, Nabais C (2014) Xylogenesis of Pinus pinaster under a Mediterranean climate. Ann Forest Sci 71:71-80

Vieira J, Campelo F, Rossi S, Carvalho A, Freitas H, Nabais C (2015) Adjustment capacity of maritime pine cambial activity in drought-prone environments. PLoS One 10:e0126223

Wei Y, Liu S, Huntzinger D, Michalak AM, Viovy N, Post WM, Schwalm C, Schaefer K, Jacobson AR, Lu C, Tian H, Ricciuto DM, Cook RB, Mao J, Shi X (2014) NACP MsTMIP: global and North American driver data for multi-model intercomparison. Data set. http://daac.ornl.gov from Oak Ridge National Laboratory Distributed Active Archive Center, Oak Ridge. doi:10.3334/ ORNLDAAC/1220

Wilkinson S, Ogee J, Domec JC, Rayment M, Wingate L (2015) Biophysical modeling of intra-ring variations in tracheid features and wood density of Pinus pinaster trees exposed to seasonal droughts. Tree Physiol. doi:10.1093/treephys/tpv01

Williams AP, Allen CD, Macalady AK et al (2013) Temperature as a potent driver of regional forest drought stress and tree mortality. Nat Clim Change 3:292-297

Woodruff DR, Meinzer FC (2011) Water stress, shoot growth and storage of non-structural carbohydrates along a tree height gradient in a tall conifer. Plant Cell Environ 34:1920-1930

Zang C, Biondi F (2013) Dendroclimatic calibration in R: the bootRes package for response and correlation function analysis. Dendrochronologia 31:68-74 